\title{
Interactive comment on "Human amplified changes in precipitation-runoff patterns in large river basins of the Midwestern United States" by Sara A. Kelly et al.
}

Sara A. Kelly et al.

sara.kelly@aggiemail.usu.edu

Received and published: 5 January 2017

See supplement for reply to comment.

Interactive comment on Hydrol. Earth Syst. Sci. Discuss., doi:10.5194/hess-2016-571, 2016. 